\title{
UAV visual signature suppression via adaptive materials
}

\author{
Ron Barrett $^{\mathrm{a}, \mathrm{b}} \quad$ Joris Melkert $^{\mathrm{a}}$ \\ ${ }^{a}$ Faculty of Aerospace Engineering, Delft University of Technology, The Netherlands \\ ${ }^{\mathrm{b}}$ Aerospace Engineering Department, Auburn University, Alabama
}

\begin{abstract}
Visual signature suppression (VSS) methods for several classes of aircraft from WWII on are examined and historically summarized. This study shows that for some classes of uninhabited aerial vehicles (UAVs), primary mission threats do not stem from infrared or radar signatures, but from the amount that an aircraft visually stands out against the sky. The paper shows that such visual mismatch can often jeopardize mission success and/or induce the destruction of the entire aircraft. A psycho-physioptical study was conducted to establish the definition and benchmarks of a Visual Cross Section (VCS) for airborne objects. This study was centered on combining the effects of size, shape, color and luminosity or effective illumance (EI) of a given aircraft to arrive at a VCS. A series of tests were conducted with a $6.6 \mathrm{ft}(2 \mathrm{~m}) \mathrm{UAV}$ which was fitted with optically adaptive electroluminescent sheets at altitudes of up to $1000 \mathrm{ft}(300 \mathrm{~m})$. It was shown that with proper tailoring of the color and luminosity, the VCS of the aircraft dropped from more than $4,200 \mathrm{~cm}^{2}$ to less than $1.8 \mathrm{~cm}^{2}$ at $100 \mathrm{~m}$ (the observed lower limit of the 20-20 human eye in this study). In laypersons terms this indicated that the UAV essentially "disappeared." This study concludes with an assessment of the weight and volume impact of such a Visual Suppression System (VSS) on the UAV, showing that VCS levels on this class UAV can be suppressed to below $1.8 \mathrm{~cm}^{2}$ for aircraft gross weight penalties of only $9.8 \%$.
\end{abstract}

Keywords: visual signature suppression electroluminescence visual stealth low observables

$\begin{array}{ccc} & \text { NOMENCLATURE } & \text { Units } \\ \text { Symbol } & \text { Description } & \mathrm{cm}^{2} \\ \text { BSOVCS } & \text { Blue Sky Overhead Visual Cross Section } & \mathrm{Lux} \\ \text { EI } & \text { equivalent illuminance } & \mathrm{Lux} \\ \text { I } & \text { illuminance } & \mathrm{cd} / \mathrm{m}^{2} \\ \text { L } & \text { luminance } & \mathrm{cm}^{2}\end{array}$

Subscripts

$100 \mathrm{~m}$

measurements taken or scaled to $100 \mathrm{~m}$ overhead altitude

\section{INTRODUCTION}

For countless millenia humans have used camouflaging techniques to hide things -- from dwellings to traps to hunters and prey. Still today, the fundamental desire not to be seen is highly desirable for many civil and military applications. Of course, the classic techniques of camouflage, concealment and deception (CCD) are often based on the same types of techniques used by our ancestors - hide objects or individuals of interest behind, within or underneath objects that blend in with the background. While this general principal is still in practice as seen in Ref. $1-4$, a different type of approach is called for when dealing with camouflaging structures like uninhabited aerial vehicles (UAVs) against a background sky.

The concept of visual stealth has its roots in a 1943 U.S. Navy project codename Yehudi. ${ }^{5,6}$ The intent of the program, which was highly secret at the time and came to light only in the 1980s, was to give Navy patrol aircraft a better chance of sinking enemy submarines. During 1942, German U-boats took a heavy toll on merchant marine shipping off the East Coast of the United States. Aircraft scrambled to attack the U-boats, but submarine captains called for crash dives whenever they spotted approaching attack planes. By the time an aircraft got close enough to sink a sub, it had disappeared. Yehudi's inventors needed a way to make the aircraft harder to see, and they realized that camouflage paint wouldn't do the job: Regardless of its color, the airplane would be a black dot against the sky. The only way to make the plane less visible was to light it up like a Christmas tree. The engineers fitted a TBM-3D Avenger torpedo-bomber with 10 sealed-beam lights, installed along the wing's leading edges 
and the rim of the engine cowling. When the intensity of the lights was adjusted to match the sky, the Avenger blended into the background. Tests proved that the Yehudi system lowered the visual acquisition range from 12 miles to two miles, allowing the Avenger to get within striking distance of its targets before they submerged. A B-24 Liberator bomber was also modified, with similar results. Yehudi was not put into production, because better radar had already enabled Navy airplanes to regain the tactical advantage, but the idea was revived after air battles over Vietnam.

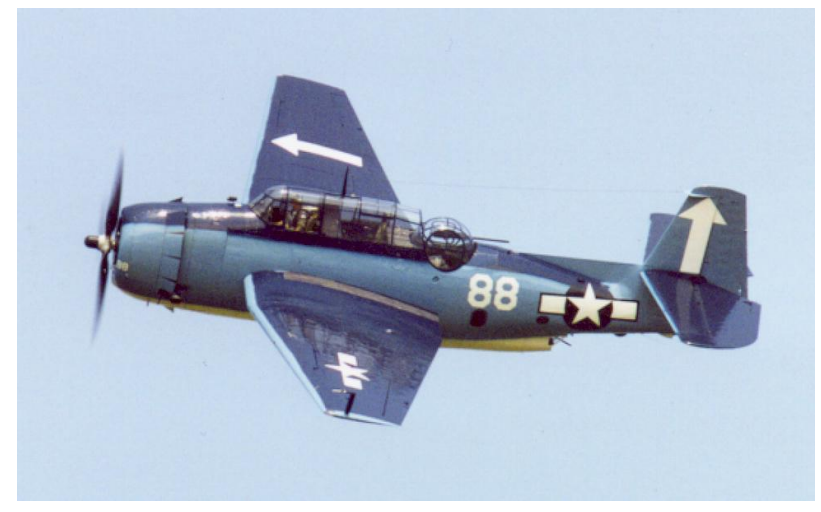

Fig. 1 The First Aircraft to Employ Active Visual Stealth Treatments -- the Grumman TBM Avenger, 1943

Concerned that the big F-4 Phantom could be seen at a greater range than its much smaller Russian adversary, the MiG-21, the Pentagon started a program called Compass Ghost. An F-4 was modified with a blue-and-white color scheme and nine high-intensity lamps on the wings and body, reducing the detection range by as much as 30 percent. It is most interesting to read that such offset lighting concepts are still being actively pursued today. ${ }^{7}$

In addition to matching the background via differential illumination in the visible spectrum, several inventions have been conceived which work to make the aircraft wings and fuselage match the background in the infrared spectrum. ${ }^{8,9,10}$ Although a worthy goal, typically the thermal signatures of the propulsors generate the largest infrared signature, rather than the skin of the aircraft. Accordingly, much more effort has been and is currently being placed on suppressing the signature of UAVs in the visible spectrum.

One very interesting method of visual camouflage is through the use of fiber optic transfer mechanisms. ${ }^{11}$ By gathering light from one side of the aircraft, contiguous fiber optic lines can transfer that image to the other side of the aircraft. Although it consumes no power, the weight penalty is prohibitive and losses in the fibers and packing arrangement induce a prohibitive luminescence undermatch with respect to the background.

To skirt these undermatch problems, modern methods of visual stealth have used active techniques. The overall scheme is to measure the color and luminosity of the background, then project it on the opposite side of the aircraft. A number of programs have been centered on variants of this concept. ${ }^{12-17}$ Although various forms of illumination mechanisms and feedback loops are described, all require relatively complicated and costly treatments which require major overhauls of the aircraft for installation. Accordingly, it is the purpose of this investigation to lay out a much less expensive method of achieving a reduced visual signature through the use of optically adaptive materials.

\subsection{UAV Missions}

\section{MOTIVATION}

Current challenges in global theaters pose many obstacles to tactical commanders. To keep operational costs low and yet provide real-time intelligence during close quarters operations, tactical and subscale UAVs are being used ever more frequently. From reports of service personnel, it is quite evident that the visual signatures of nearly all classes of UAVs which are currently fielded are far too high to provide an element of surprise for certain types of operations. Because some operations rely upon complete surprise, the spotting of a UAV, although not leading to loss of the aircraft, will lead to mission failure. Accordingly, visual signature suppression is absolutely critical for some missions. 


\subsection{Physical Threats to Aircraft at Varying Altitudes}

In addition to mission failure, it can be observed that a high visual signature can lead to the loss of the entire aircraft. Because mission commanders are demanding ever closer examination of targets, operational altitudes of UAVs are being pushed lower and lower. These low operational altitudes expose aircraft to threats which are different than those experienced from aircraft operating at higher altitudes as seen in Fig. 2.

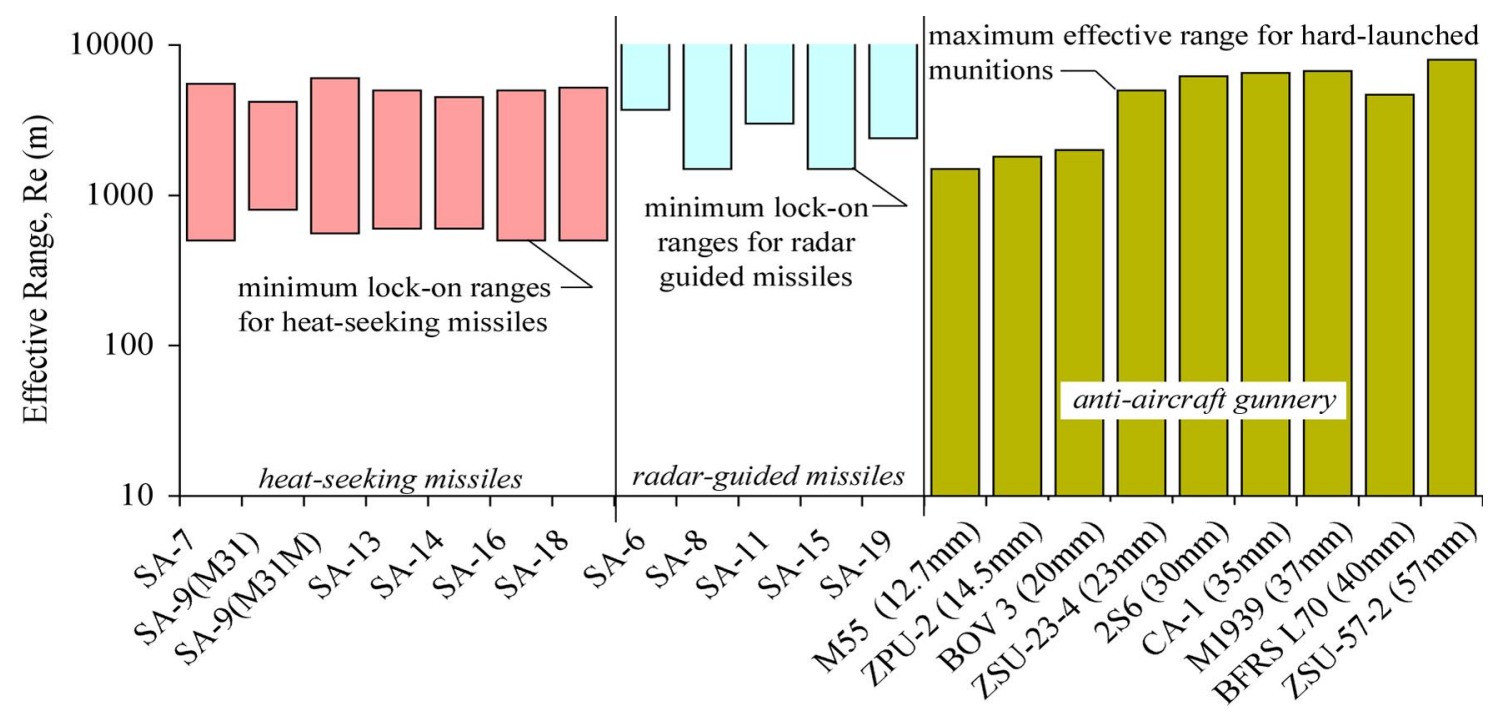

Figure 2 Effective Minimum and Maximum Ranges of a Range of Anti-Aircraft Weapons ${ }^{18}$

Because UAVs are operating ever more frequently at lower altitudes, from Fig. 2, it can be seen that they are exiting the useful ranges for most radar- and infrared-guided missiles as they dip below 2,000 $\mathrm{ft}(600 \mathrm{~m})$ of altitude. Indeed, several classes of UAVs are regularly operating under forest canopies, in the urban canyon and even lower. ${ }^{19,20}$ Because anti-aircraft gunnery is the weapon system of choice for engaging aircraft flying at these low altitudes, it is important to counter its guidance and tracking methods with appropriate forms of stealth. Because human ears and eyes are most often used for primary detection, masking the noise and visual appearance of such aircraft is absolutely critical.

\subsection{Definition}

\section{VISUAL CROSS SECTION}

After a search of the body of open technical literature, it is obvious that no suitable technical definition exists to define how much a given aircraft stands out against a background sky. After much experimentation and surveying both aircraft and human subjects, it is clear that a term and associated definition which includes physical characteristics and psycho-ocular interpretations is needed. In an effort to approach the problem of visual signature in a scientific manner, a new technical term is hereby proposed:

\section{Blue-Sky Overhead Visual Cross Section (BSOVCS):}

The Blue-Sky Overhead Visual Cross Section of an aircraft at a given flight state is deemed to be the area of a silhouetted lampblack disk at $100 \mathrm{~m}$ altitude directly overhead against a cloudless blue sky at less than $50 \%$ humidity with the sun at a $40^{\circ}$ to $50^{\circ}$ angle to the disk-aircraft-observer plane such that the majority of a statistical sample of no less than 10 observations from individuals with 20-20 vision declares the disk to be just as obvious as the observed aircraft, given a 10 sec. observation time and a flight motion of the aircraft and the disk at arc rates with respect to the observer which are representative of the aircraft at the given flight state, considering the disk and aircraft traveling in the same direction as they pass overhead. 
The authors hope that the technical community will adopt the above definition of BSOVCS in the same way that the terms "Radar Cross Section" and "Infrared Signature" are currently used. The reader is asked to note that although the definition above allows for the scientific measurement of BSOVCS, it is still broad enough to take into account nearly all aircraft sizes, configurations, attitudes, flight speeds and levels of biomimesis. It should also be noted that the "Blue-Sky Overhead" background is not the only measurement conditions which can and should be used to assess aircraft VCS. Accordingly, it will be important to establish uniform conditions to measure aircraft VCS against various forms of clouds from dawn to dusk against a variety of atmospheric coloration. Still, for the purposes of this investigation only, the BSOVCS is proposed as a "first benchmark" for determining the VCS of an aircraft at a given flight state.

\subsection{Measurement}

To implement the definition above, a sampling of subjects must be recruited and their vision tested. Unlike RCS or IR signature testing, BSOVCS testing takes into account not only the physical characteristics of the aircraft, but also the psycho-optical human response to such stimulation. Subjects are seated and told which areas of the sky to watch on a cloudless, blue sky day with the sun at angles from 40 to $50 \mathrm{deg}$ from a vertically oriented flight plane extending from the observer vertically. The subjects are asked to turn away from the sun so that they are not partially blinded by its glare. A glass panel with a scaled lampblack dot is placed $30 \mathrm{~cm}$ in front of the observer. Typically, for bottom-view BSOVCS measurement of slow-flying UAVs, the aircraft is orbited above the observers while they are shown various glass plates with different dot sizes till the matching sizes are found. Once ten or more samples are taken, such that the majority of the subjects find that the aircraft and the dot are "equally obvious" the area of the dots are averaged, then multiplied by $111,111(100 \mathrm{~m} / 0.3 \mathrm{~m})^{2}$ to arrive at the BSOVCS for that aircraft flying at that flight state only.

\section{VISUAL SIGNATURE SUPPRESSION (VSS) SYSTEM}

\subsection{VSS Design and Installation on 2m UAV}

To demonstrate the effectiveness of active visual signature suppression, a VSS system was installed on a $6.6 \mathrm{ft}$ $(2 \mathrm{~m})$ fixed-wing UAV. The "Gentle Lady" UAV is a low subsonic aircraft powered by $2.5 \mathrm{cc}$ displacement internal combustion engine and is capable of reaching speeds of approximately $50 \mathrm{ft} / \mathrm{s}(30 \mathrm{kts}, 34 \mathrm{mph}, 15 \mathrm{~m} / \mathrm{s})$. The VSS system used $13 \mathrm{mil}(330 \mu \mathrm{m})$ thick electroluminescent (EL) sheets driven up to $6 \mathrm{kHz}$ at up to $150 \mathrm{~V}$. A DC chopper inverter provided power to the EL sheets which were mounted to the underside of the wing, tail and fuselage skins with tape adhesive. High energy density lithium polymer batteries powered the inverter, which, in turn drove the EL sheets. Figure 3 shows the Gentle Lady during launch and free flight with no VSS installed on the aircraft.

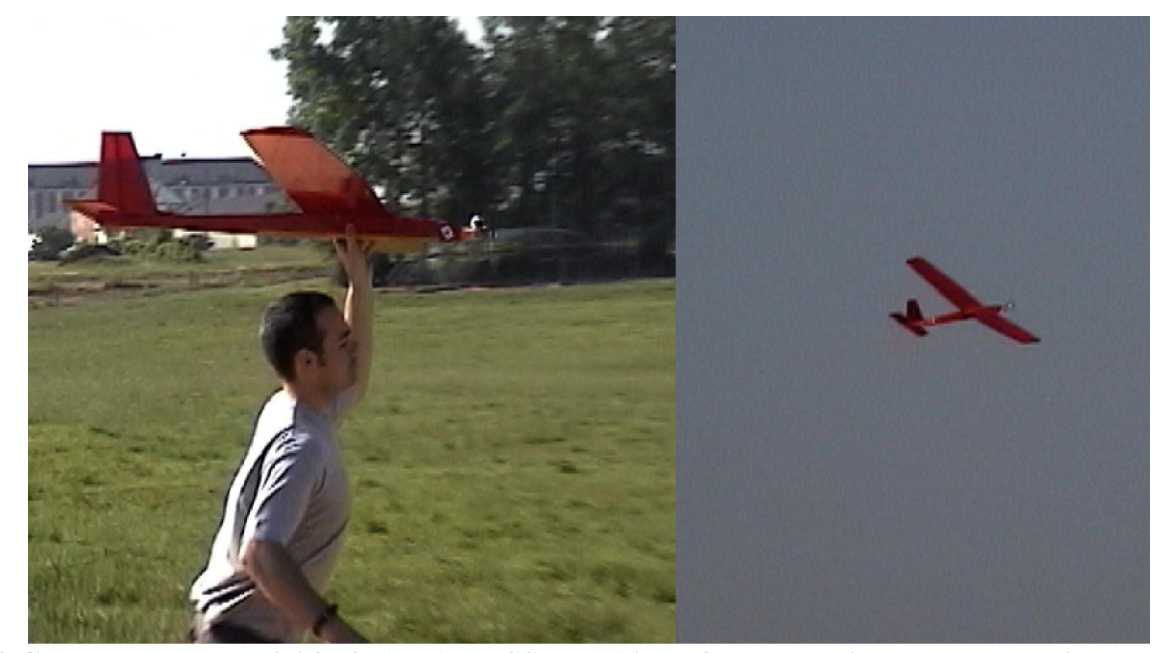

Fig. 3 Gentle Lady Type 6.6 ft (2m) UAV VSS Test Aircraft Type during Launch and in Free Flight 


\subsection{Electroluminescent Sheet Performance}

The Gentle Lady UAV was treated with $4.64 \mathrm{ft}^{2}\left(0.43 \mathrm{~m}^{2}\right)$ of $13 \mathrm{mil}(330 \mu \mathrm{m})$ thick electroluminescent (EL) sheet on the underside of the aircraft which was selected to match the pale blue of a mid-day sky. The polymeric EL material was fitted to match the underside of the aircraft and bonded with Scotchweld ${ }^{\mathrm{TM}}$ adhesive throughout. Electrical leads were routed along the surface and penetrated the skin at downstream locations so as not to disturb local airflows. Every effort was made to maintain good surface waviness so as not to induce an increment in drag.

To measure the performance of the EL sheet in a useful manner with respect to aircraft VCS, a term "equivalent illuminance" EI (Lux) is coined. This term is hereby defined as: "Equivalent Illuminance is the measurement of illuminance by direct contact against the luminescent side of an electroluminescent sheet with a calibrated light meter." This measurement allows a simple and useful way to determine the performance of EL sheets as they would be in flight against a background sky. EI can be thought of as if the aircraft would be flying with no on-board light sources and $100 \%$ reflective paint, illuminated only by a light source from the ground. This is a different form of measurement than that made with luminosity $\left(\mathrm{cd} / \mathrm{m}^{2}\right)$ which is significantly more complicated and is generally tailored toward measurements from light sources such as light bulbs.

The EL material was powered by an on-board power supply feeding a chopped square-wave of varying frequency from 1 to $6 \mathrm{kHz}$ at up to 150V. Figure 4 shows a spike in EI at higher voltages as well as a rise in driving frequency which is optimum for maximizing EI. Although the EI spike above $140 \mathrm{~V}$ might be considered as a "positive" development, the high EI is above most background sky levels (excluding, of course those aspect angles close to the sun, with or without clouds). Accordingly, it is of little value to operate in this condition.

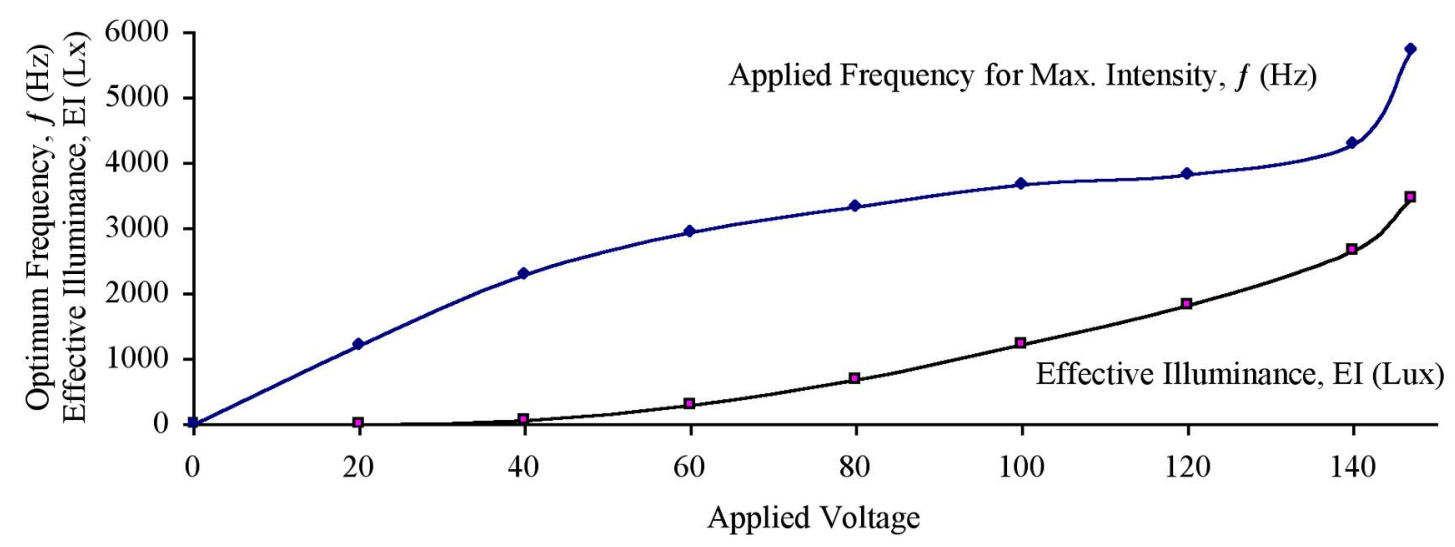

Fig. 4 Effective Illuminance, Applied Frequency and Driving Voltage of VSS Electroluminescent Sheets

The power consumed by the VSS system was considerable, but not unexpected for a proof-of-concept type aircraft. It can be seen from Fig. 5 that an EI spike and dip in power consumption occurs near $145 \mathrm{~V}$ of driving voltage at $5500 \mathrm{~Hz}$.

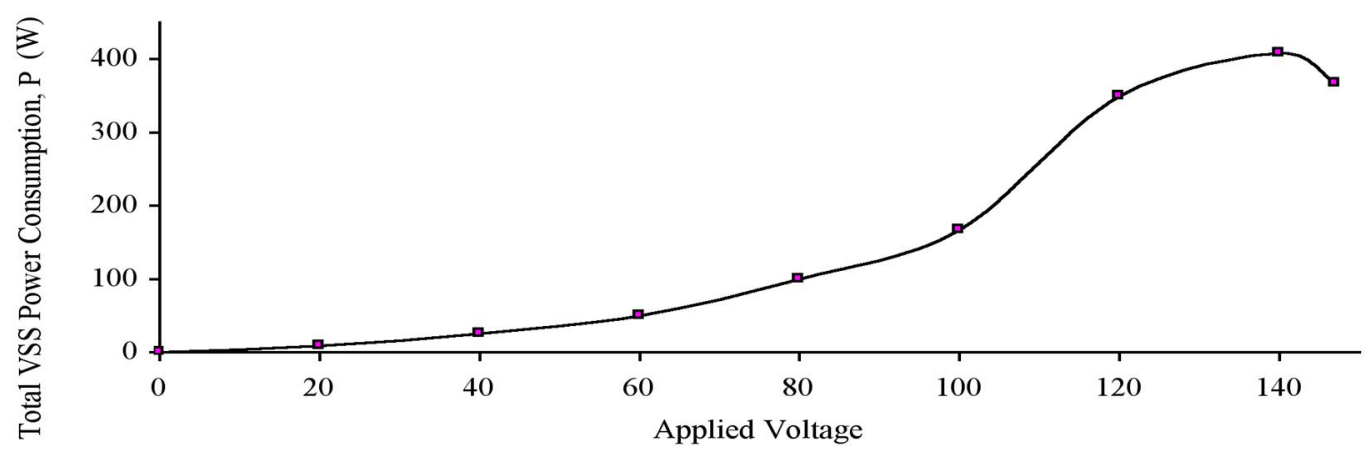

Fig. 5 VSS System Total Electrical Power Consumed as a Function of Applied Voltage at Optimum Driving Frequency 
The true demonstration of the system-level effectiveness is seen in flight. Figure 6 shows a close up of the VSS system operating at $5 \mathrm{~m}$ altitude at 40V, 88V, and 120V (EI $=59 \mathrm{Lux}, 900 \mathrm{Lux}, 1819$ Lux respectively).

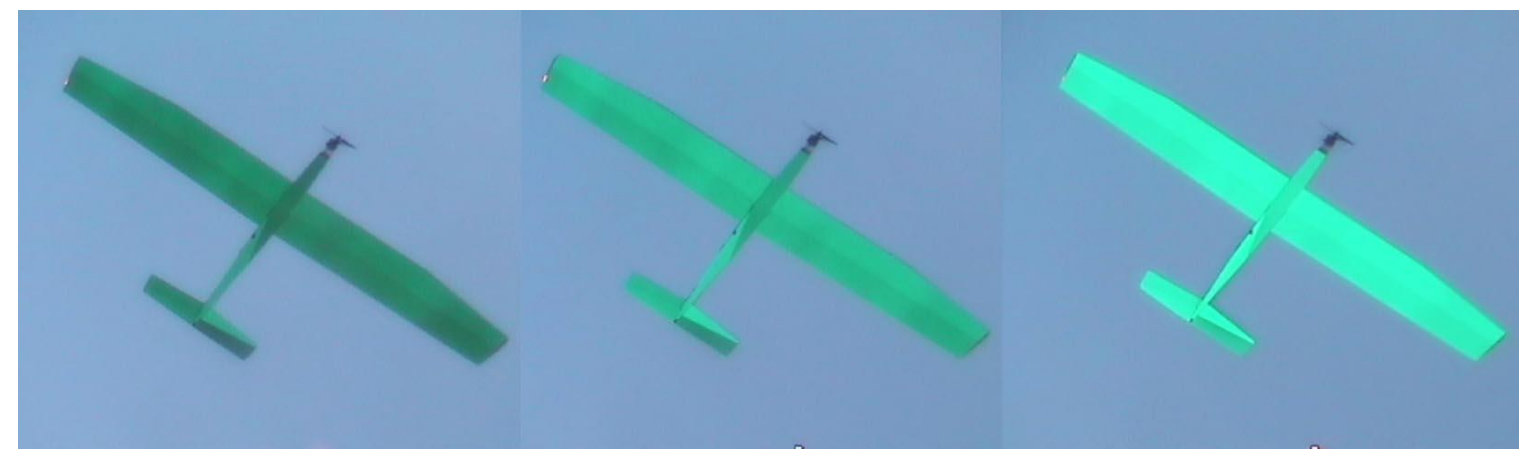

Fig. 6 Luminosity Undermatch, Match and Overmatch of VSS UAV Against a Mid-Day Blue Sky, 16 ft (5m) Altitude

Of course, $16 \mathrm{ft}(5 \mathrm{~m})$ of operating altitude is unusual for $6.6 \mathrm{ft}(2 \mathrm{~m})$ class UAVs. Accordingly, tests were also conducted to show the effectiveness of the background match at $1,000 \mathrm{ft}(300 \mathrm{~m})$. Figure 7 was recorded with a 640 x 480 camera under mixed-sky conditions so as to show the effects of blue sky and clouds at greater altitudes and distances.

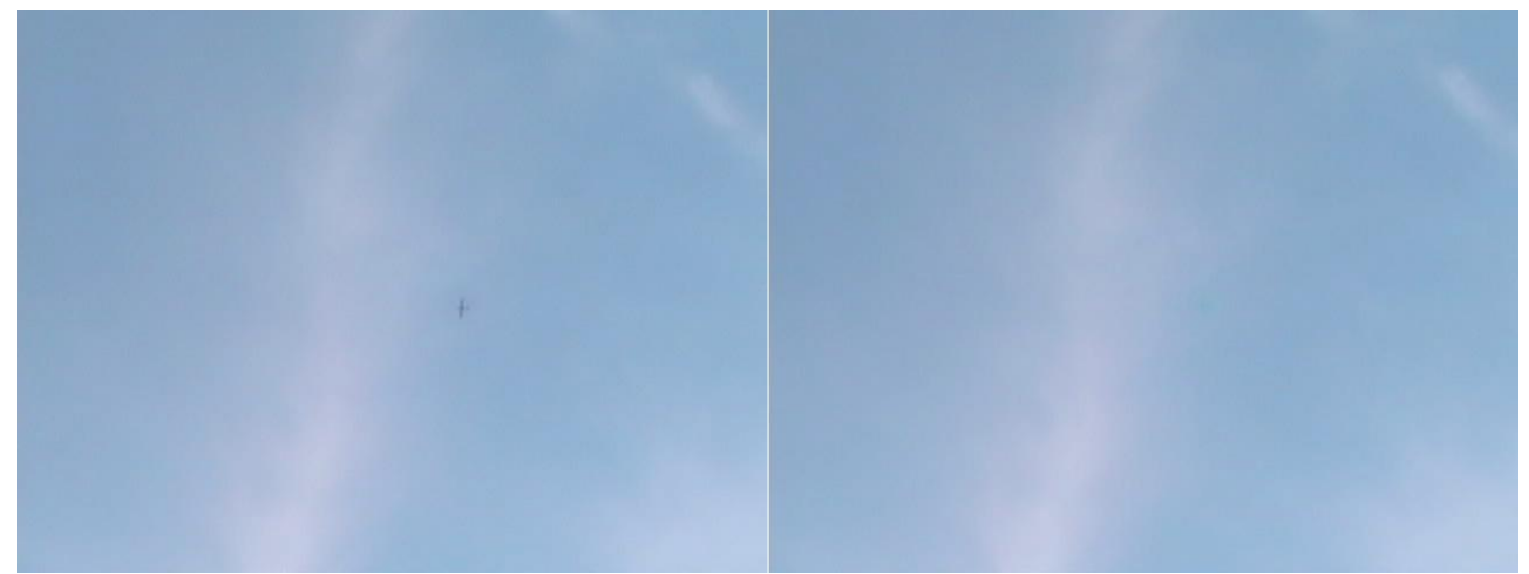

Fig. 7 Luminosity Undermatch and Match of VSS UAV Against a Mid-Day Blue Sky, 1,000 ft (300m) Altitude $\mathrm{V}=88$ Volts, $\mathrm{EI}=900 \mathrm{Lux}, \mathrm{P}=127 \mathrm{~W}, f=3700 \mathrm{~Hz}($ each frame resolution $=640 \mathrm{x} 480$ pixels, printed here $@ 213 \mathrm{dpi})$

Fig. 7 clearly shows that the aircraft essentially disappears against the background sky. From Fig. 6, it is clear that the color and luminescence distribution is mismatched against the sky. However, at greater distances, it is easy to see that the match of the gross luminescence or equivalent illuminance is much more important than color match or uniformity. A close-up of Fig. 7 shows that with the system off, the UAV is clearly silhouetted against the sky, however, even with an obviously imperfect match at low altitudes, at high altitudes, the details are blurred and the aircraft effectively disappears. 

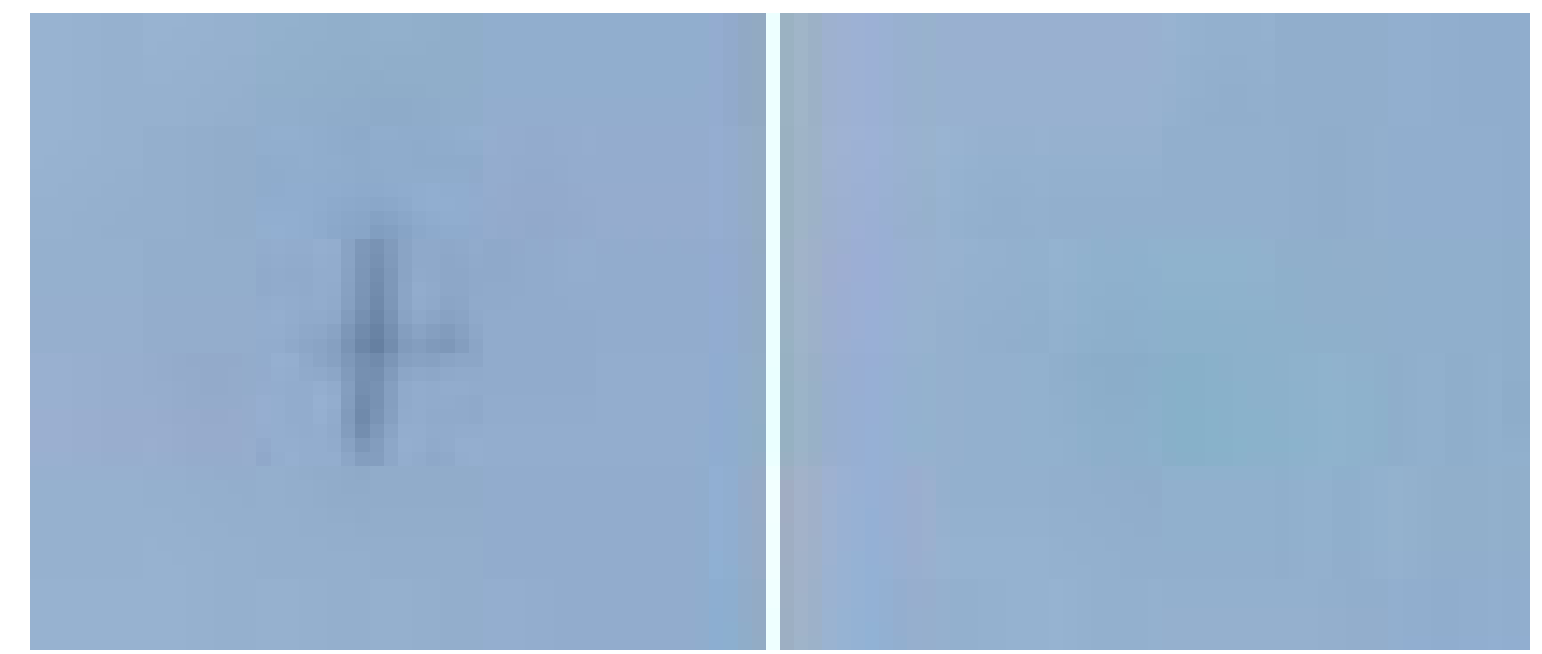

Fig. 8 Zoom-in Details of Fig. 7 (above) Luminosity Undermatch and Match of VSS UAV Against a Mid-Day Blue Sky, $1000 \mathrm{ft}(300 \mathrm{~m})$ Altitude, $\mathrm{V}=88 \mathrm{Volts}, \mathrm{EI}=900 \mathrm{Lux}, \mathrm{P}=127 \mathrm{~W}, f=3700 \mathrm{~Hz}$ (each frame resolution $=52 \times 45$ pixels)

Another demonstration that the gross effective illuminance or luminosity is more important than an accurate color match or spot illuminance distribution is seen when the background shifts to that of a passing cloud. The whiteness of the background forms an even stronger effective surface making the dark aircraft stand out more. However, from Fig. 9, the same power setting as used in Fig.'s 7 and 8 yields the same results: the aircraft disappears.

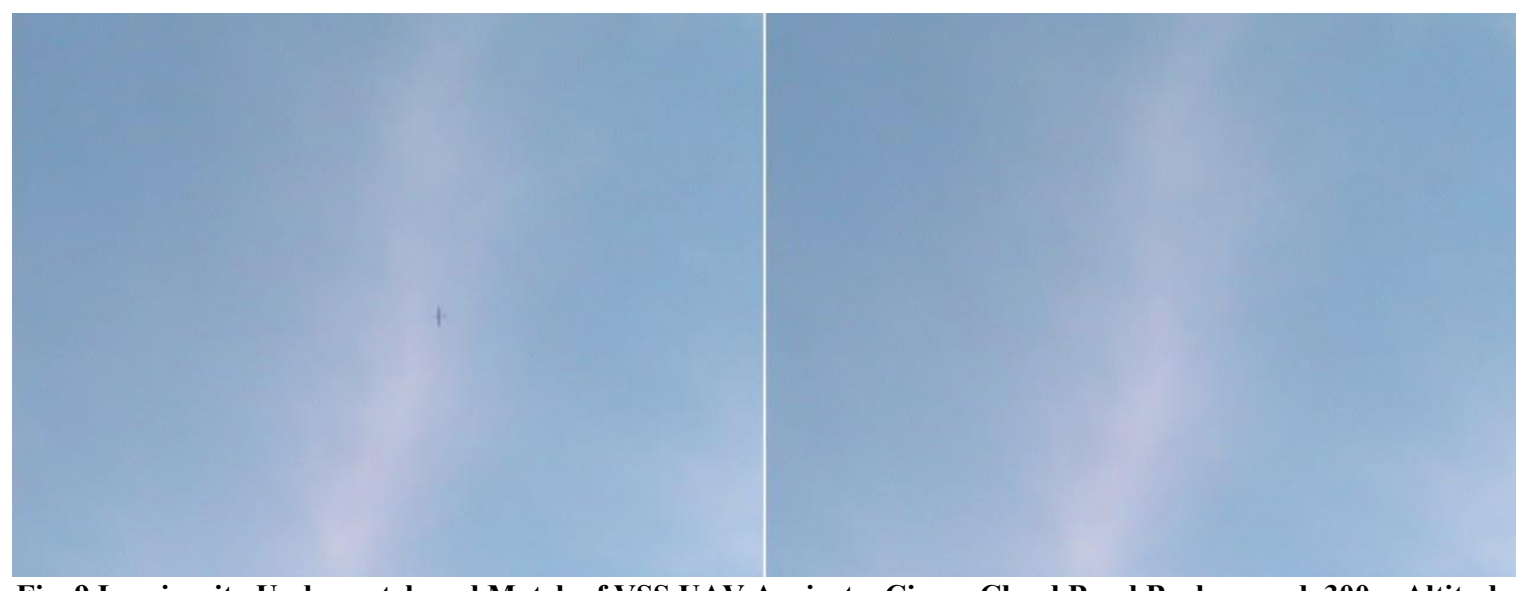

Fig. 9 Luminosity Undermatch and Match of VSS UAV Against a Cirrus Cloud Band Background, 300m Altitude $\mathrm{V}=88 \mathrm{Volts}, \mathrm{EI}=900 \mathrm{Lux}, \mathrm{P}=127 \mathrm{~W}, f=3700 \mathrm{~Hz}($ each frame resolution $=640 \times 480$ pixels, printed here $@ 213 \mathrm{dpi})$

Given the definition of BSOVCS, a group of 10 volunteers, each with 20/20 vision was recruited for a test. At an altitude of $1,000 \mathrm{ft}(300 \mathrm{~m})$, the aircraft was illuminated at various levels. The VCS criteria of Section 3.1 was used to determine the BSOVCS quantatively. It can be seen that as the applied voltage and corresponding power consumption increased, the BSOVCS decreased till approximately $120 \mathrm{~V}$ which is close to the middle of a weak minimum. It should be noted that $1.8 \mathrm{~cm}^{2}$ is the averaged observed lower limit for visibility for this sample group, which ranged from $1.1 \mathrm{~cm}^{2}$ to $6.5 \mathrm{~cm}^{2}$. 


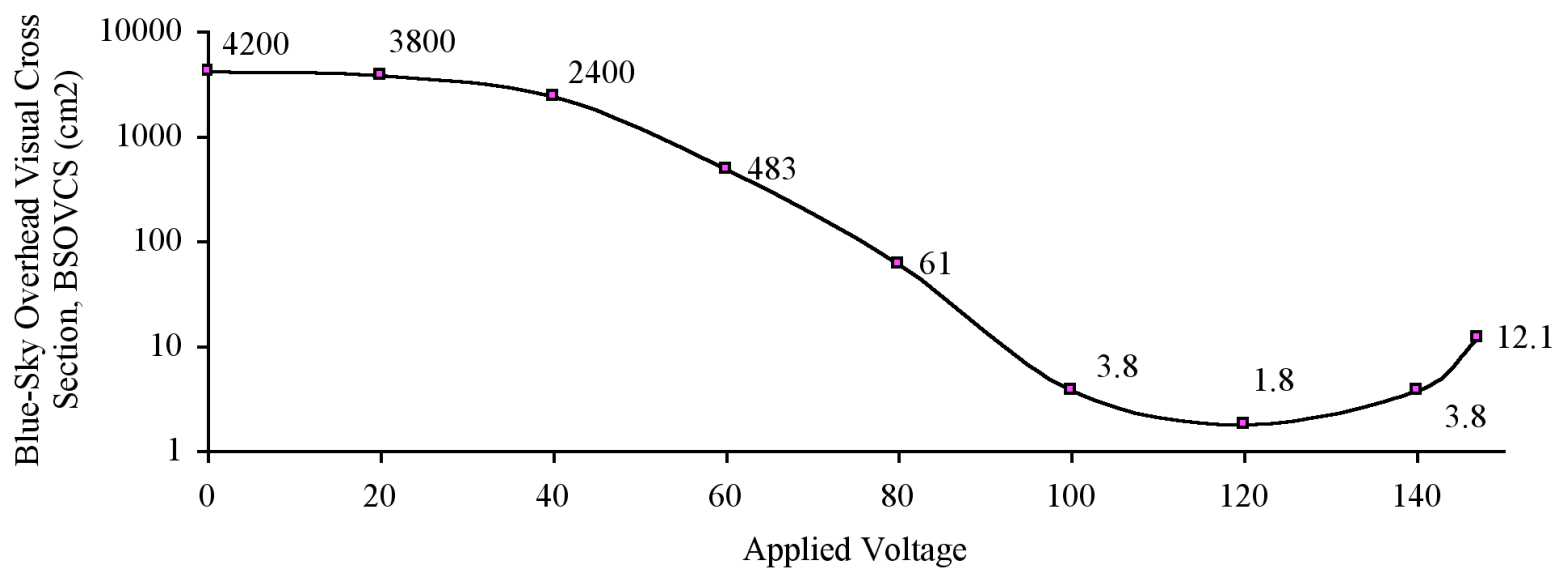

Fig. 10 Blue-Sky Overhead Visual Cross Section $\left(\right.$ BSOVCS $\left._{100 m}\right)$ with Applied Voltage on the VSS Demonstrator UAV

\subsection{System-Level Impact on Aircraft Mission Performance}

The primary impact that the VSS system will have on gross aircraft performance will come from the weight impact. Because the aerodynamic characteristics of the aircraft are not affected, the drag polar will remain unchanged. however, the weight impact can be seen in Table 1. Clearly, a 90\% weight growth is not suitable for most classes of UAVs. By examining Table 1, it can be seen that two components are the primary contributors to the additional weight: EL Sheets and Battery. Because the aircraft takes advantage of an internal combustion powerplant, several classes of electrical generators are suitable for use in powering the VSS system. It is also envisioned that direct power generation without the use of a heavy inverter can be used. If such a system could be made, then the weight penalty for a full VSS system would be decreased to approximately $63 \%$. Although the VSS system weight penalty for the Gentle Lady type UAV is indeed considerable, other types of UAVs operating at higher flight speeds will be reduced dramatically. Further, there will be significantly positive trends with increased aircraft size as the weight fractions of the VSS sheeting will decrease linearly with increases in aircraft size. It is estimated that the weight fractions of the power supplies and driving electronics will decrease with the square of the scale factor. Accordingly, for an aircraft with a $20 \mathrm{~m}$ wingspan (rather than the $2 \mathrm{~m}$ of the Gentle Lady), the weight fractions of the EL sheets will decrease from $38.1 \%$ to $3.81 \%$ while the power supply will drop from $51.9 \%$ to $0.5 \%$, leading to a total weight penalty on the order of $4.3 \%$ for the entire aircraft.

Table 1 Comparison of Baseline Gentle Lady and $100 \%$ Coverage VSS-Equipped UAV

\begin{tabular}{|l|c|c|}
\hline & Baseline Aircraft & $\begin{array}{c}100 \% \text { VSS Modified } \\
\text { Aircraft }\end{array}$ \\
\hline Wiring & - & $0.28 \mathrm{oz}(8 \mathrm{~g})$ \\
\hline EL Sheets & - & $7.61 \mathrm{oz}(216 \mathrm{~g})$ \\
\hline Driving electronics & - & $1.8 \mathrm{oz}(51 \mathrm{~g})$ \\
\hline Battery $\left(10\right.$ min.) $\left(\right.$ BSOVCS $\left._{100 \mathrm{~m}}<1.8 \mathrm{~cm}^{2}\right)$ & - & $8.3 \mathrm{oz}(235 \mathrm{~g})$ \\
\hline Gross weight & $20 \mathrm{oz}(567 \mathrm{~g})$ & $38.5 \mathrm{oz}(1077 \mathrm{~g})$ \\
\hline Weight Growth & - & $18 \mathrm{oz}(510 \mathrm{~g}) 90 \%$ \\
\hline
\end{tabular}

Because complete coverage of the aircraft underside is not necessary given translucent and/or transparent structural materials, substantial weight reductions can be obtained by using such materials in most places. Accordingly, the only areas which must therefore employ a VSS type system for visual suppression would be those which cannot be made transparent like electronics bays, flight controls and powerplant assemblies. To demonstrate this, a proof-of-concept Gentle Lady UAV was made with such translucent materials. The total amount of EL material was reduced from $4.64 \mathrm{ft}^{2}\left(668 \mathrm{in}^{2}, 4310 \mathrm{~cm}^{2}\right)$ to $31.8 \mathrm{in}^{2}\left(205 \mathrm{~cm}^{2}\right)$, representing a $95.2 \%$ reduction. This reduction in total materials used resulted in a substantial drop in weight and power increment. Because translucent structural materials were used, a 2.1\% weight growth was experienced. Structural materials like clear polyester skins and polycarbonate spars, stringers, bulkheads and longerons were used successfully. 
Although fully capable of carrying all operational loads, their weight is slightly greater than the balsa-wood, fiberglass and graphite which is typically used in the original Gentle Lady UAV. However, the combined effect was a marked improvement over the baseline $100 \%$ coverage VSS system as seen in Table 2:

Table 2 Comparison of Baseline Gentle Lady and 4.8\% Coverage VSS-Equipped UAV

\begin{tabular}{|l|c|c|}
\hline & $\begin{array}{c}\text { Baseline } \\
\text { Aircraft }\end{array}$ & $\begin{array}{c}4.8 \% \text { VSS Modified } \\
\text { Transparent Aircraft }\end{array}$ \\
\hline Aircraft Structure & - & $0.64 \mathrm{oz}(18 \mathrm{~g})$ \\
\hline Wiring & - & $0.07 \mathrm{oz}(2 \mathrm{~g})$ \\
\hline EL Sheets & - & $0.36 \mathrm{oz}(10 \mathrm{~g})$ \\
\hline Driving electronics & - & $0.5 \mathrm{oz}(14 \mathrm{~g})$ \\
\hline Battery $(60 \mathrm{~min}).\left(\mathrm{BSOVCS}_{100 \mathrm{~m}}<1.8 \mathrm{~cm}^{2}\right)$ & - & $0.38 \mathrm{oz}(11 \mathrm{~g})$ \\
\hline Gross weight & $20 \mathrm{oz}(567 \mathrm{~g})$ & $23.8 \mathrm{oz}(675 \mathrm{~g})$ \\
\hline Weight Growth & - & $1.95 \mathrm{oz}(55 \mathrm{~g}) 9.7 \%$ \\
\hline
\end{tabular}

Clearly, the $4.8 \%$ coverage transparent UAV experiences a much smaller weight impact than the $100 \%$ coverage aircraft. From Tables 1 and 2, it can be seen that a beneficial, nonlinear scaling effect is observed in the battery weight. This is because the entire VCS of the aircraft starts out at a lower level than the $100 \%$ coverage aircraft. This lower baseline makes it easier to achieve a BSOVCS $_{100 \mathrm{~m}}<1.8 \mathrm{~cm}^{2}$ at lower local luminosity levels than used in the $100 \%$ coverage aircraft. The reader is also asked to note that the total VSS on time of the $4.8 \%$ coverage aircraft was increased from $10 \mathrm{~min}$. to a full hour. In spite of the increased operational time, the total system internal volume impact was only $3.2 \mathrm{in}^{3}(52 \mathrm{cc})$. Accordingly, it is easy to see that the $4.8 \%$ coverage VSS UAV has passed a basic threshold of viability for fielding. To illustrate the utility of the concept Figure 11 shows the $4.8 \%$ coverage aircraft with full VSS at $100 \mathrm{~m}$ in flight under blue sky conditions.

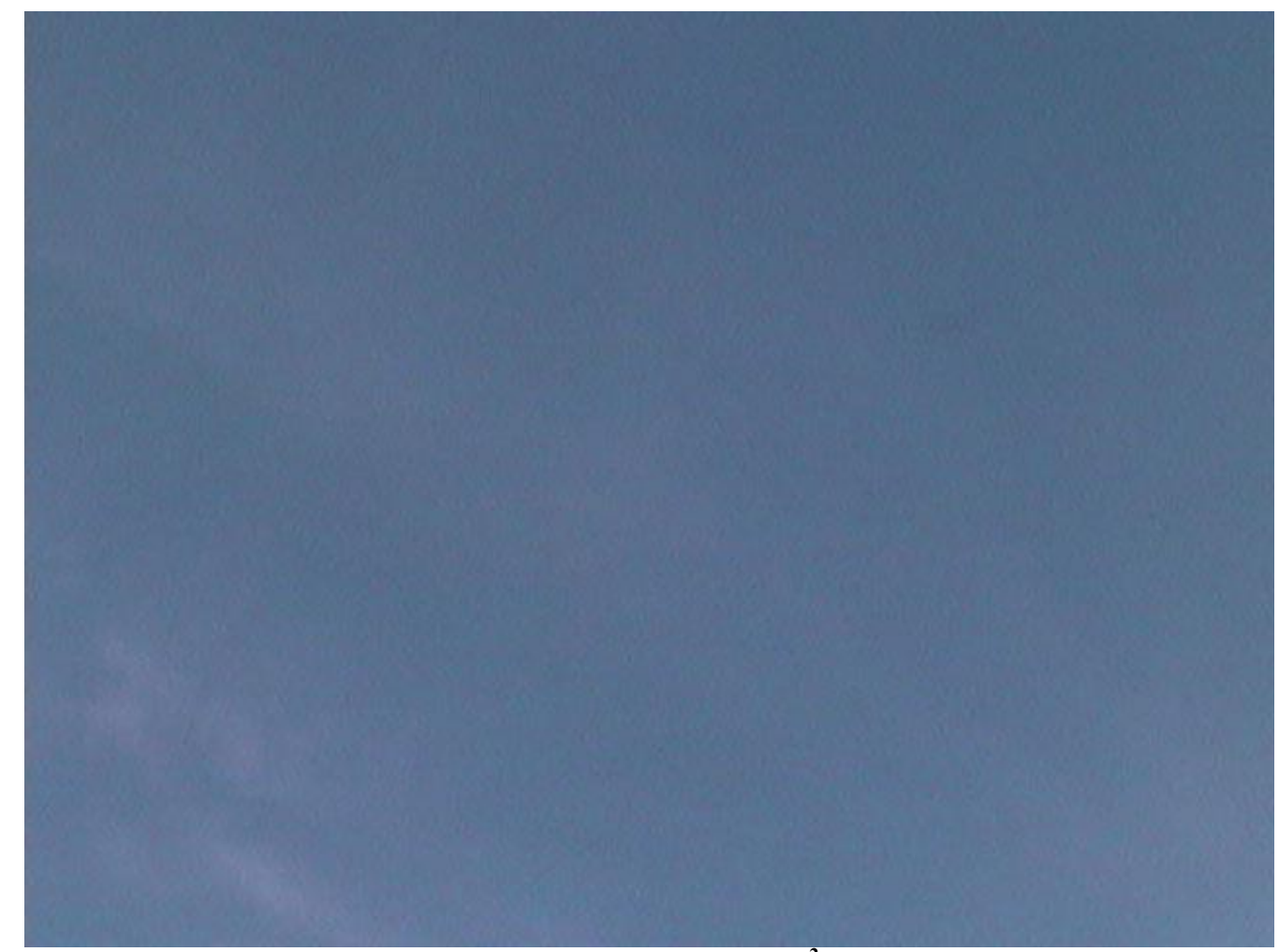

Fig. 11 4.8\% VSS Coverage Transparent UAV at BSOVCS $_{100 \mathrm{~m}}<1.8 \mathrm{~cm}^{2} 100 \mathrm{~m}$ Altitude, Under Blue-Sky Conditions $\mathrm{V}=60$ Volts, $\mathrm{EI}=299 \mathrm{Lux}, \mathrm{P}=2.4 \mathrm{~W}, f=2940 \mathrm{~Hz}$ (each frame resolution $=640 \times 480$ pixels, printed here $@ 120 \mathrm{dpi})$ 


\section{CONCLUSIONS}

It can be concluded that the Visual Signature Suppression (VSS) System successfully suppresses the visual signature of a $6.6 \mathrm{ft}(2 \mathrm{~m})$ class UAV to levels which are not detectable by the naked human eye. It can also be concluded that the bulk of the threats of physical destruction of UAVs flying below altitudes of $3,000 \mathrm{ft}(1 \mathrm{~km})$ come not from radar- and infrared-guided missiles, but most often from small arms and anti-aircraft artillery. Because these weapon systems are very frequently visually trained, possession of a low Visual Cross Section (VCS) is shown to be very important. The VSS system installed on the test UAV was shown to possess significant overmatch capability with respect to blue sky illumination levels. Overhead testing at $5 \mathrm{~m}$ showed that at $88 \mathrm{VAC}, 3700 \mathrm{~Hz}$, the system generated and equivalent illuminance (EI) of $900 \mathrm{Lux}$ which was deemed to statistically match the background EI under blue sky overhead conditions. At these conditions, the VSS system consumed $126 \mathrm{~W}$ of power and had a total system weight of $18.5 \mathrm{oz}(524 \mathrm{~g})$. This extra load represented a significant system weight penalty. Still, in spite of the weight penalties, the VSS system was shown to be highly effective, suppressing VCS levels to only $1.8 \mathrm{~cm}^{2}$ at $100 \mathrm{~m}$ which is below the observed lower limit for individuals with $20 / 20$ vision to detect silhouetted objects at $100 \mathrm{~m}$. A second aircraft was fabricated to demonstrate the potential of the system given translucent aircraft structures with the VSS being used on only a select few internal components which could not be made translucent. It was shown that with a weight penalty of only $9.7 \%$ gross weight, the VCS levels could be suppressed to under $1.8 \mathrm{~cm}^{2}$. Accordingly, it can be concluded that for minimal weight impact, the $6.6 \mathrm{ft}(2 \mathrm{~m})$ class UAVs can essentially be made invisible to the naked eye.

\section{ACKNOWLEDGMENTS}

The authors would like to acknowledge the outstanding contributions of the many students and colleagues who helped with this study including Mr. Christoph Burger, Mike Brennison and Ms. Lori Prothero. This study

was sponsored by the AAL and the Faculty of Aerospace Engineering of the Delft University of Technology, The Netherlands.

\section{REFERENCES}

1. Heiniger, F., "Camouflage Structure," US Pat. 6,605,340 issued 12 August 2003.

2. Rothgeb, S. B., Bacon, K. S., and Swiney, R. L. Jr., "Structure for Concealing Telecommunication Antennas," US Pat. Application, 10/622,840, published 29 April 2004.

3. Anitole, G., "Building Shape Modification Camouflage Structures,” US Pat. 6,257,262, issued 10 July 2001.

4. Spanier, J. and Spanier, F., "Method and Assembly for Camouflaging at Least one Building," US Pat. 4,294,308 13 October 1981.

5. Sweetman, W. and Douglass, S., "Hiding in Plane Sight - Stealth Aircraft Own the Night, Now They Own the Day," Popular Science, May 1997, pgs. 54-59.

6. Sweetman, W., “The Invisible Men,” Air \& Space Magazine, May 1997, pgs. 18-27.

7. Schlenker, W. E., “On-Board Camouflage Lighting System using Directional Light Sources,” US Pat. 6,459,076 issued 1 October 2002.

8. Reynolds, R. F. and Kinsella, M. J., "Thermal and Visual Camouflage System,” US Pat. 6,338,292 issued 15 January 2002.

9. Leupolz, A., Scherber, W., Rothmund, W., "Infrared Camouflaging System,” US Pat. 6,753,075 issued 22 June 2004. 
10. Conway, T. G., McClean, R-L G. and Walker, G. W.," Three Color Infrared Camouflage System, "Three Color Infrared Camouflage System," US Pat. 5,077,101 31 December 1991.

11. Grippin, R. R., “Fiber Optic Camouflage,” US Pat. 5,220,631 issued 15 June 1993.

12. Bettinger, D. S., "Orthogonal Projection Concealment Apparatus," US Pat. 6,333,726 issued 25 December 2001.

13. Larue, J. L., "Camouflaged Structure and method of Camouflaging a Structure against a Background Having a Generally Uniform Composition," US Pat. Application 10/726,205 1 December 2003.

14. Schowengerdt, R. N., "Cloaking System using Optoelectronically Controlled Camouflage,” US Pat. 5,307,162 issued 26 April 1994.

15. Alden, R. M., "Multi-Perspective Background Simulation Cloaking Process and Apparatus," US Pat. Application, 09/970,368 11 July 2002.

16. Alden, R., "Three-Dimensional Signature Control Process and Apparatus with Military Application," US Pat. Application 10/266,371 13 March 2003.

17. Alden, R. M., "Three-Dimensional Receiving and Displaying Process and Apparatus with Military Application," US Pat. Application 10/132,331 29 August 2002.

18. Anon., "Rest of World Military Equipment," Federation of American Scientists web site http://www.fas.org, Washington, DC, February 2005.

19. Barrett, R. and Lee, G., "Design Criteria, Aircraft Design, Fabrication and Testing of Sub-Canopy and Urban Micro-Aerial Vehicles," proceedings of the AIAA/AHS International Powered Lift Conference, Alexandria, Virginia, 1 November 2000.

20. Barrett, R., "Adaptive Aerostructures, Improving High Performance, Subcale Military UAVs," $45^{\text {th }}$ AIAA/ASME/ASCE/AHS/ASC Structures, Structural Dynamics and Materials Conference, $12^{\text {th }}$ AIAA/ASME/AHS Adaptive Structures Conference 19 - 22 April 2004/Palm Springs, California, AIAA paper no. 2004-1886.

21. Mueller, C. G., Rudolph, M., "Light and Vision," Life Science Library, published by Time-Life Books, New York, 1972. 